Article

\title{
Performance of Practical Grounding Systems under High Impulse Conditions
}

\author{
Muhd Shahirad Reffin, Normiza Mohamad Nor*, Nurul Nadia Ahmad and Syarifah Abdullah \\ Faculty of Engineering, Multimedia University, Jalan Multimedia, Cyberjaya 63100, Malaysia; \\ muhd_shahirad@yahoo.com (M.S.R.); nurulnadia.ahmad@mmu.edu.my (N.N.A.); synina@gmail.com (S.A.) \\ * Correspondence: normiza.nor@mmu.edu.my; Tel.: +60-038-312-5387
}

Received: 23 October 2018; Accepted: 14 November 2018; Published: 16 November 2018

\begin{abstract}
This paper investigates the factors affecting the impulse characteristics of purposely built grounding systems. We installed $2 \mathrm{~m} \times 2 \mathrm{~m}$ grounding systems in four different sites with different soil resistivity values. The effect of impulse polarity on soil characteristics was also investigated for different soil resistivity. A circular ring electrode was used as a return electrode in all four sites. For one of the sites, different configurations of grounding systems were installed to allow the study of the effect of ground electrode configurations on soil characteristics. The aim of this study was to quantify the effects of soil resistivity, impulse polarity, and earth electrode configurations on soil electrical properties under high impulse conditions by field measurements. The new data could be useful in understanding the characteristics of grounding systems in various factors under high impulse conditions. It is hoped that by considering these factors, it can help optimize the design of earthing systems.
\end{abstract}

Keywords: grounding systems; impulse characteristics; impulse polarity; soil characteristics; soil resistivity

\section{Introduction}

Extensive investigations on the impulse characteristics of grounding systems have been presented in many research studies [1-10]. The studies can be classified into three different approaches; field, laboratory and computational methods. The type of study may depend on the availability of equipment, budget and the purpose of study. From these studies [1-9], it can be concluded that highly nonlinear soil behaviour is exhibited by grounding systems under fast impulses. Some research studies [1-10] have investigated the factors affecting the discharge processes in soil that take place when the earth electrode is subjected under fast impulses; soil resistivity, earth electrode configurations, impulse polarity, current response time and soil layers. Most of these studies $[9,10]$ were performed using a laboratory approach under controlled conditions. The studies $[9,10]$ are useful in providing a better understanding of the conduction mechanisms in soil under fast impulse currents, and determining the factors affecting the soil characteristics under high impulse currents more accurately.

Some studies [1-8] have also been directed towards investigations on the impulse characteristics of grounding systems by field measurements. Impulse testing and measurements on practical grounding systems can provide a valuable information on the impulse characteristics of grounding systems in real-world scenarios. However, it was found that the research on factors affecting soil characteristics under high impulse conditions by field measurement is still limited. Among the studies done in this area [1-8], field testing and measurements on practical grounding systems under impulse conditions have so far investigated the effect of high impulse current on soil resistivity, earth electrode configurations, impulse polarity and remote earth arrangement on soil characteristics. However, the number of studies are limited, and no standard earth electrode configurations were used in their analysis for different soil resistivity [1-8]. Hence, no direct comparison can be made on the transient performance of grounding 
systems in different soil resistivity. This can be seen from the work published by Sekioka et al. [1], Yunus et al. [3] and Abdullah et al. [8], whom investigated the effect of ground electrodes and soil resistivity on the performance of grounding systems under impulse conditions. All of these studies $[1,3,8]$ found that the lower the earth resistance value at steady-state, or DC resistances, RDC, the lower the current dependence. However, the studies $[1,3,8]$ did not use the standard configuration at different sites. In this present paper, a standard configuration for grounding systems is used at all sites.

Lightning performance of distribution and transmission systems requires evaluation of grounding systems under different impulse polarity. From previous studies [7,11], the characteristics of grounding systems under different impulse polarities has been reported. Etobi et al. [7] used a single rod electrode subjected under both impulse polarities, where the investigations were done by field measurement. Higher impulse resistance values were found in negative polarity than that for positive polarity. The study in [7] however, only considered a single rod, installed at one site,with one soil resistivity condition. It was found by Cabrera et al. [11] by laboratory measurement, that the effect of impulse polarity becomes significant in high resistivity soils. To the authors' knowledge, very limited study has been reported or publised on the effect of impulse polarity on practical grounding systems. For this reason, this paper is to contribute towards a good understanding of practical grounding systems under different impulse polarities. When many more improved tests and analytical techniques are conducted, a better knowledge of the subject can be achieved. From the lightning data of each region or country, information on the positive and negative strikes is normally available. This data can be closely related to the characteristics of grounding systems installed in different soil resistivities. Thus, some improvement can be made on the grounding systems installed in soils with high resistivity in the regions that are prone to negative lightning strikes, since this paper revealed that the effect of impulse polarity is more likely significant for grounding systems installed in high resistivity soil.

At the moment, the study is intended as an initial stage of proposing the design for grounding grid considering the soil ionization process. The study shows that the current standard for the assessment of practical grounding systems by low voltage and low frequency is inadequate, and it needs to consider the performance of practical grounding systems under high impulse conditions.

\section{Experimental Arrangement}

Four different sites, with different soil resistivity were selected in this study. Sites 1 and 2 are within the university's campus, and $5 \mathrm{~km}$ apart from each other. Sites 3 and 4 are located $50 \mathrm{~km}$ and $100 \mathrm{~km}$ away from the university's campus respectively.

\subsection{Soil Resistivity at Site}

Using a standard earth tester, the Wenner method as outlined in IEEE Standard 81 [12] was applied, to obtain the soil resistivity values for each site. Current Distribution, Electromagnetic Fields, Grounding and Soil Structure Analysis (CDEGS) software was used to interpret the measured data into a 2-layer soil model. Table 1 shows the soil resistivity for all the four sites. As can be seen, Site 3 had the highest soil resistivity in both the upper and lower layers. Site 4 had the lowest soil resistivity, where its lower layer had the resistivity of $0.65 \Omega \mathrm{m}$.

Table 1. Soil resistivity values for different sites

\begin{tabular}{ccccc}
\hline Location & $\boldsymbol{\rho}_{\mathbf{1}}\left(\boldsymbol{\Omega} \cdot \mathbf{m}^{-\mathbf{1}}\right)$ & $\mathbf{h}_{\mathbf{1}}(\mathbf{m})$ & $\boldsymbol{\rho}_{\mathbf{2}}\left(\boldsymbol{\Omega} \cdot \mathbf{m}^{-\mathbf{1}}\right)$ & $\mathbf{h}_{\mathbf{2}}(\mathbf{m})$ \\
\hline Site 1 & 119.5 & 7.18 & 391.05 & $\infty$ \\
Site 2 & 53.89 & 5.19 & 426.89 & $\infty$ \\
Site 3 & 210.96 & 1.73 & 507.62 & $\infty$ \\
Site 4 & 52.74 & 1.02 & 0.65 & $\infty$ \\
\hline
\end{tabular}




\subsection{Ground Electrodes under Test}

For the investigation of the effect of high impulse current on soil characteristics for different soil resistivities, a standard dimension of ground rod electrodes were installed at four different sites. Four ground rod electrodes, $20 \mathrm{~mm}$ in diameter and $1.5 \mathrm{~m}$ long, were fixed to the ground, with $0.5 \mathrm{~m}$ of the rod length left exposed above the ground surface. Copper mesh of $25 \mathrm{~mm}$ width and a thickness of $2 \mathrm{~mm}$ was used to provide connection points to each ground rod electrode, as shown in Figure 1.

For the investigation of the soil characteristics under high impulse currents on ground electrode configurations, three different configurations were used, and all were installed at Site 1 . The ground rod electrodes are; 1-rod electrode, 2-rod and 3-rod electrodes. Each ground rod electrode is $20 \mathrm{~mm}$ in diameter and $1.5 \mathrm{~m}$ long, they were fixed to the ground with $0.5 \mathrm{~m}$ left exposed. For 2-rod and 3-rod electrodes, a copper mesh of $25 \mathrm{~mm}$ width and thickness of $2 \mathrm{~mm}$ was used to connect from one rod to another, that was separated by $3 \mathrm{~m}$.

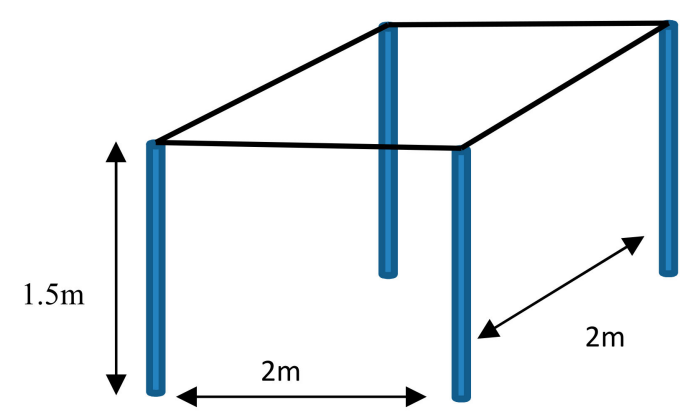

Figure 1. A grounding grid of $2 \mathrm{~m} \times 2 \mathrm{~m}$ for the tests at different sites.

\subsection{Remote Ground Electrodes}

For the impulse tests on four ground electrodes installed at Sites 1, 2, 3 and 4, a standard configuration of a ring grounding system with a $4 \mathrm{~m}$ diameter, shown in Figure 2, was used at all four sites. The remote electrode consisted of 8 rods in a circular ring configuration with a $4 \mathrm{~m}$ diameter. Each rod electrode had the same dimensions as presented in Part B, which was also buried at $1 \mathrm{~m}$, with $0.5 \mathrm{~m}$ left exposed. Each rod electrode was interconnected using a copper mesh of $25 \mathrm{~mm}$ width and thickness of $2 \mathrm{~mm}$. The remote earths were defined as REA, REB, REC and RED to represent the remote earths used for sample A, B, C and D respectively.

The remote ground electrode used for ground electrode tests for 1,2 and 3-rod electrodes is a $20 \mathrm{~m}$ $\times 30 \mathrm{~m}$ grounding grid shown in Figure 3. Spacing between copper strips for $20 \mathrm{~m}$ was $5 \mathrm{~m}$ apart, and for $30 \mathrm{~m}$ was $15 \mathrm{~m}$ apart. Hard copper strips of $30 \mathrm{~mm}$ width and $2 \mathrm{~mm}$ thick were used. The copper strips were buried $300 \mathrm{~mm}$ below the earth's surface, and were exothermically welded to the rod electrodes. Twelve rod electrodes were used, with each one being $20 \mathrm{~mm}$ in diameter, and $1.8 \mathrm{~m}$ long.

In this study, the distance between the grounding systems under test and remote earth was kept at $30 \mathrm{~m}$ for all tests.

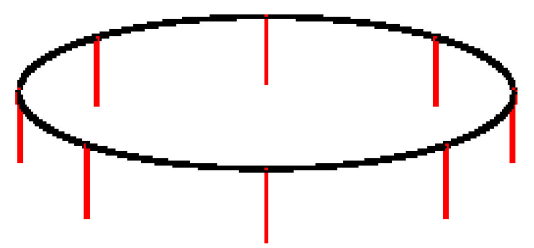

Figure 2. A $4 \mathrm{~m}$ diameter of remote earth for impulse tests on a $2 \mathrm{~m} \times 2 \mathrm{~m}$ grounding grid at different sites. 


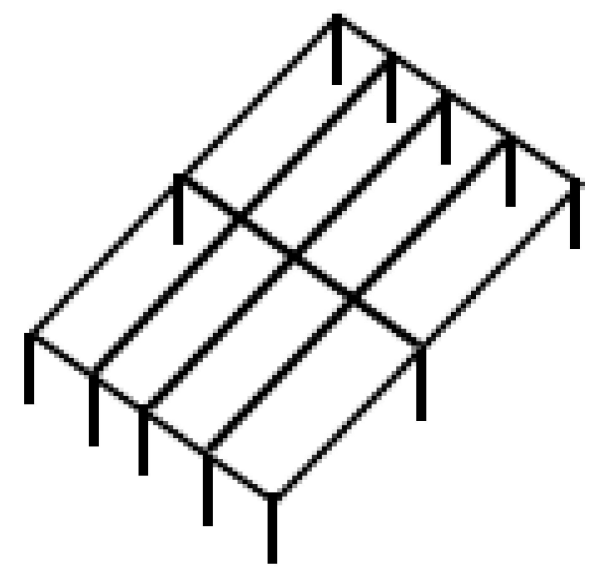

Figure 3. A mesh $20 \mathrm{~m} \times 30 \mathrm{~m}$ of remote earth for impulse tests on single-rod, 2-rod and 3-rod electrodes.

\subsection{Resistances of Grounding Systems}

Using a standard earth tester, a Fall-of-Potential (FOP) method was used to obtain the DC resistance values of each electrode configuration at different sites. Table 2 summarizes the DC resistance values of grounding systems, together with the resistance values computed by CDEGS. As can be seen, Sample A had the highest RDC, due to high soil resistivity in Site 1 and the small dimensions of the earth electrode (single-rod electrode). On the other hand, sample D had the lowest RDC due to low soil resistivity in Site 4 .

Table 2. RDC of electrode under tests and remote earth.

\begin{tabular}{cccccc}
\hline \multicolumn{3}{c}{ Electrode under Tests } & \multicolumn{3}{c}{ Remote Earth } \\
\hline Earth Electrode & Measured $(\boldsymbol{\Omega})$ & CDEGS $(\boldsymbol{\Omega})$ & Earth Electrode & Measured $(\boldsymbol{\Omega})$ & CDEGS $(\boldsymbol{\Omega})$ \\
\hline Sample A & 61.5 & 38.386 & REA & 38.2 & 23.237 \\
Sample B & 12.86 & 14.463 & REB & 13.67 & 9.8906 \\
Sample C & 62.6 & 56.708 & REC & 51.8 & 38.154 \\
Sample D & 4.66 & 6.1194 & RED & 4.13 & 3.1764 \\
1-rod & 466 & 132.18 & $20 \mathrm{~m} \times 20 \mathrm{~m}$ & 8.45 & 3.5 \\
2-rod & 185 & 70.507 & $20 \mathrm{~m} \times 20 \mathrm{~m}$ & 8.45 & 3.5 \\
3-rod & 118 & 49.119 & $20 \mathrm{~m} \times 20 \mathrm{~m}$ & 8.45 & 3.5 \\
\hline
\end{tabular}

Table 2 also indicates different values of RDC obtained by measurements and CDEGS. This could be due to the soil conditions at the time when the measurement were made, such as weather/seasonal time and presence of adjacent metallic buried structures and ground wires in the soil, which may divert a substantial amount of the test current, as described in Reference [13]. However, it is outside the scope of this paper to detail these differences. As can be noted from Table 2, the RDC of both remote earths were lower than the RDC of the grounding systems under tests. This is in accordance to IEEE Standard 81 [12], which requires having lower RDC values of remote earth than RDC of grounding systems under tests.

\subsection{Test Set Up}

A diagram of the experimental setup used for the impulse tests is shown in Figure 4. A mobile three-stage impulse generator, mounted on the lorry, was used in this study and was capable of generating high voltages of up to $300 \mathrm{kV}$, and high current impulses up to $10 \mathrm{kA}$. A diesel generator was used to supply the power for the impulse generator. A current transformer with $20 \mathrm{MHz}$ bandwidth and $0.01 \mathrm{~V} / \mathrm{A}$ sensitivity was used for current measurement. A resistive divider with a ratio of 3890:1, and a response time of 40 ns was used for voltage measurements. 


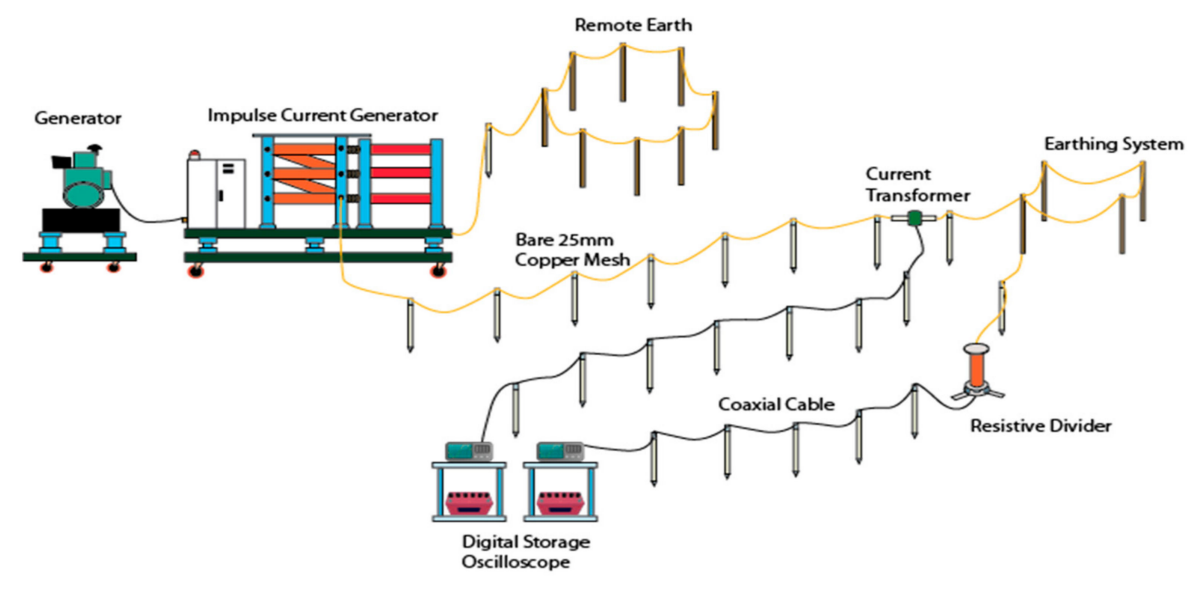

Figure 4. Test set up.

The voltage and current signals were captured on a Lecroy HDO4000, $500 \mathrm{MHz}$ Digital Storage Oscilloscope (DSO) (New York, NY, USA). As shown in Figure 4, the voltage and current signals were captured on two separate Digital Storage Oscilloscopes (DSO). This was to avoid any residual voltage that may have built up during measurements. Copper strips used for the connections were isolated from the earth, by hanging the copper strips over the epoxy insulation rods. A $1 \mathrm{~m}$ long rod electrode was buried as the ground for the resistive divider.

\section{Test Results}

Impulse tests with different current magnitudes were conducted on 4-rod ground electrodes installed at four different sites, with different soil resistivity. For the purpose of a better understanding of soil behavior under different impulse polarity, the 4-rod ground electrodes were also subjected under both impulse polarities. In one of the sites, three different configurations were used to high impulse currents, to determine the effects of earth electrode's configurations on soil characteristics. In each test, the injection point is always at the electrode that is at the nearest location to the remote earth. This is to provide some controlled in the tests, since in some studies [14,15], the effect of injected point was observed. For the purpose of a better understanding of soil behavior under high-impulse currents, the results are discussed according to impulse shape, front and discharge time response and impulse resistance of the test object under the effects of soil resistivity, impulse polarity and earth electrode's configuration.

\subsection{Effect of Soil Resistivity}

Figures 5-8 show the voltage and current traces obtained with tests on 4-rod electrodes installed at sites 1, 2, 3 and 4 respectively, which were subjected to a charging voltage of $30 \mathrm{kV}$. Both voltage and current traces had fast rise times, and the current appears to have had a similar impulse shape to the voltage trace on both front and decay times, which indicates a predominantly linear resistive behavior. It was also noted that a large voltage drop occurred in samples $\mathrm{A}$ and $\mathrm{D}$ from its charging voltage. When the charging voltage of $30 \mathrm{kV}$ was used, less than $10 \mathrm{kV}$ voltage level was applied to the test load.

Some oscillations on the impulse voltage were noted in Figure 5 for sample A, and a careful examination of the voltage trace revealed that these oscillations disappeared at a charging voltage of $120 \mathrm{kV}$, as shown in Figure 9. The origins and causes of these oscillations are not well understood, despite numerous repeated tests that were conducted on it. In Figure 7, some delay occurred on the voltage trace at a charging voltage of $30 \mathrm{kV}$, where the cause of this delay is also unknown, despite some repeated tests that were done on the test sample. At a slightly higher voltage level, no delay between the current and voltage trace was seen, as shown in Figure 10 for a charging voltage of $50 \mathrm{kV}$.

It was also observed that at higher voltage level, the oscillations on the front impulse current trace were noted, as can be seen in Figure 11. However, it was noticed that the oscillations on the front impulse current trace was only noticed in Sample A, B and D, at applied voltage of $16 \mathrm{kV}, 12 \mathrm{kV}$ and 
$12.5 \mathrm{kV}$, respectively. These initial oscillations on the front impulse current were not seen for Sample $\mathrm{C}$, though the applied voltage had reached more than $70 \mathrm{kV}$, and with currents of more than $4000 \mathrm{~A}$. The observable effect of these initial oscillations on the current traces may be explained by the initial discharge effect occurring in the soil, which can lead to a breakdown phenomenon at higher voltages. Table 3 summarizes the charging and applied voltages and its corresponding peak current at which oscillations started to appear on the current trace.

From the figures, it was also noted that there are differences in the time to discharge to zero of the current trace. The time to discharge to zero of the current traces was estimated at different charging voltage levels. Figure 12 shows the times to discharge to zero of the current traces for samples A, B, C and $\mathrm{D}$ with different peak currents. The time to discharge of the current trace was found to be lower for lower resistivity soil and was also found to decrease with voltage magnitudes. The slower rate of discharge to zero of the current traces in high resistivity soil is likely due to the relatively large value of resistance. At lower current levels, it would be expected that lower conduction levels in the soil cause the system to discharge more slowly. For higher voltages, there is better and faster conduction in the soil, thus the current impulse shape discharged quickly to the ground. These results are found to be similar to the findings obtained in References $[9,10]$. However, their studies $[9,10]$ are done with laboratory experiments.

Many studies [1-10] used the impulse resistance values, $R_{\text {impulse }}$ to characterize the electrical soil behavior under high impulse conditions. In this study, impulse resistance was defined as

$$
\mathrm{V}_{\mathrm{p}} / \mathrm{I}_{\mathrm{p}}
$$

throughout this paper. As suggested in [5], this definition is valid when the impulse current occurs at the same instant of time as the peak voltage, which was observed for all test samples and at different voltage levels. Figure 13 shows the resistance values obtained for 4-rod ground electrodes at different sites/soil resistivities. It can be seen from the figure that $R_{\text {impulse }}$ values are always lower than $R D C$ for all test samples. $R_{\text {impulse }}$ also decreased with increasing current magnitudes for samples $A, B$ and $C$.

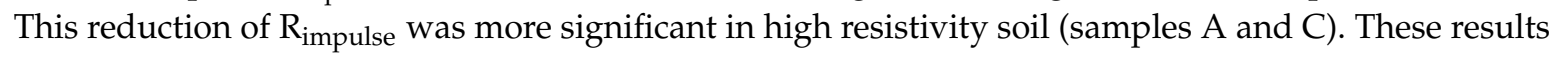
are similar to many published studies [1-10], where a decrease in $\mathrm{R}_{\text {impulse }}$ with current magnitudes indicates a possible nonlinear conduction process in the soil resulting from the soil ionization process. As can be seen in Figure 13, $R_{\text {impulse }}$ for sample D was less dependent upon current magnitudes.

The results revealed that it is possible to investigate the soil behavior in a controlled way and quantify the effect of high impulse current on soil resistivity by field measurements. This new field data suggests that it is important to include the behavior of soil under high impulse conditions in the design of grounding systems.

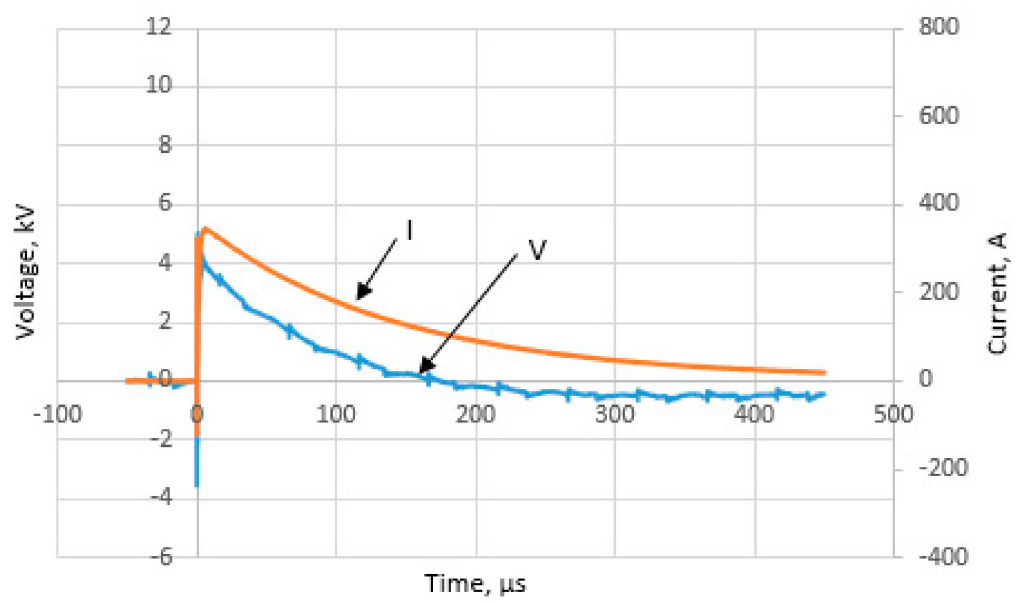

Figure 5. Voltage and current traces of positive polarity for electrodes installed at site 1 at a charging voltage of $30 \mathrm{kV}$. 


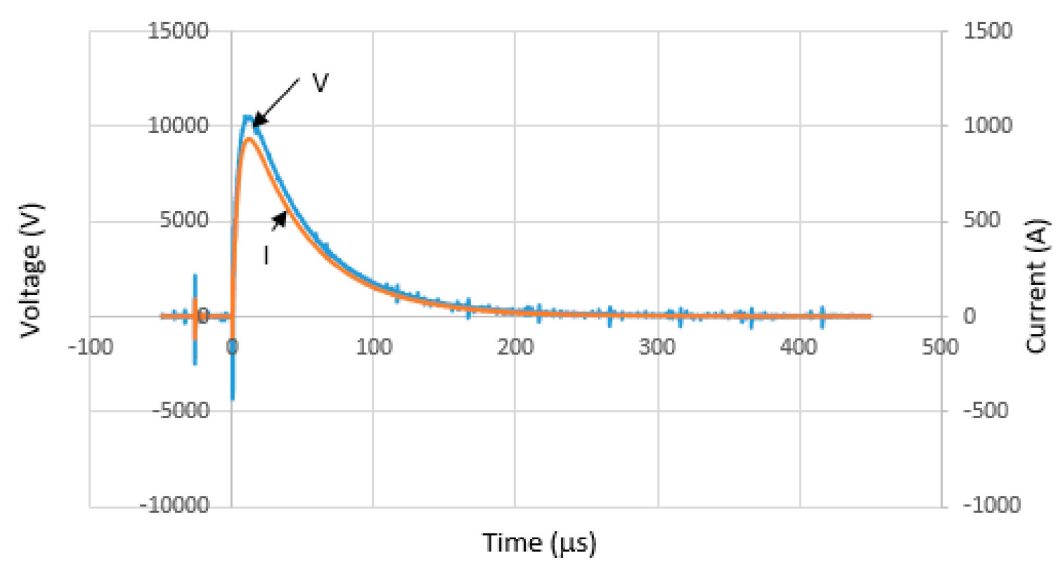

Figure 6. Voltage and current traces of positive polarity for electrodes installed at site 2 at a charging voltage of $30 \mathrm{kV}$.

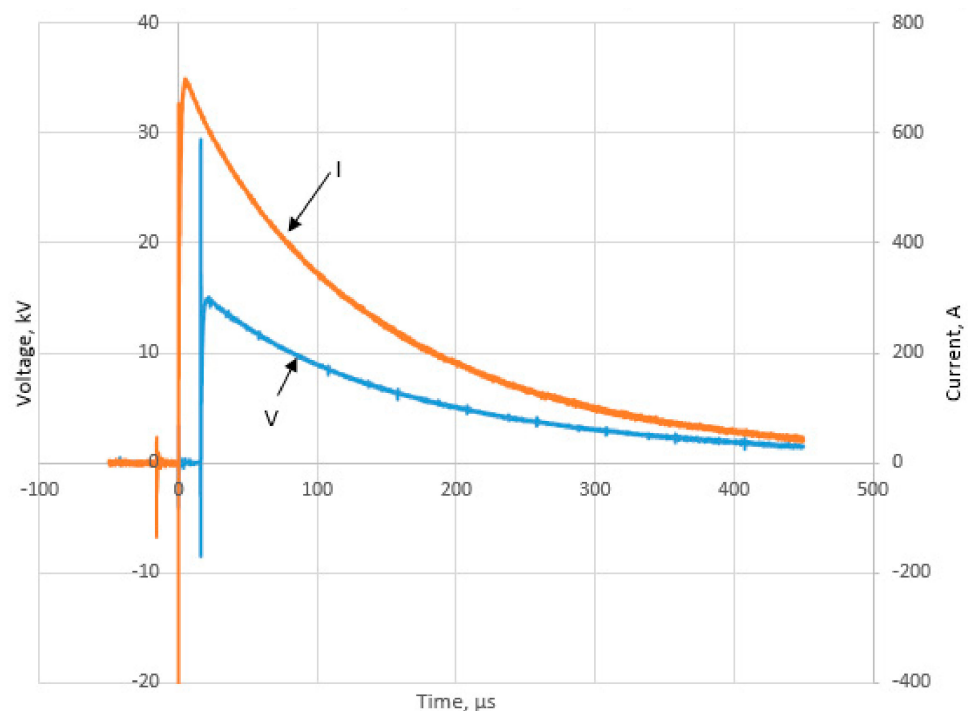

Figure 7. Voltage and current traces of positive polarity for electrodes installed at site 3 at a charging voltage of $30 \mathrm{kV}$.

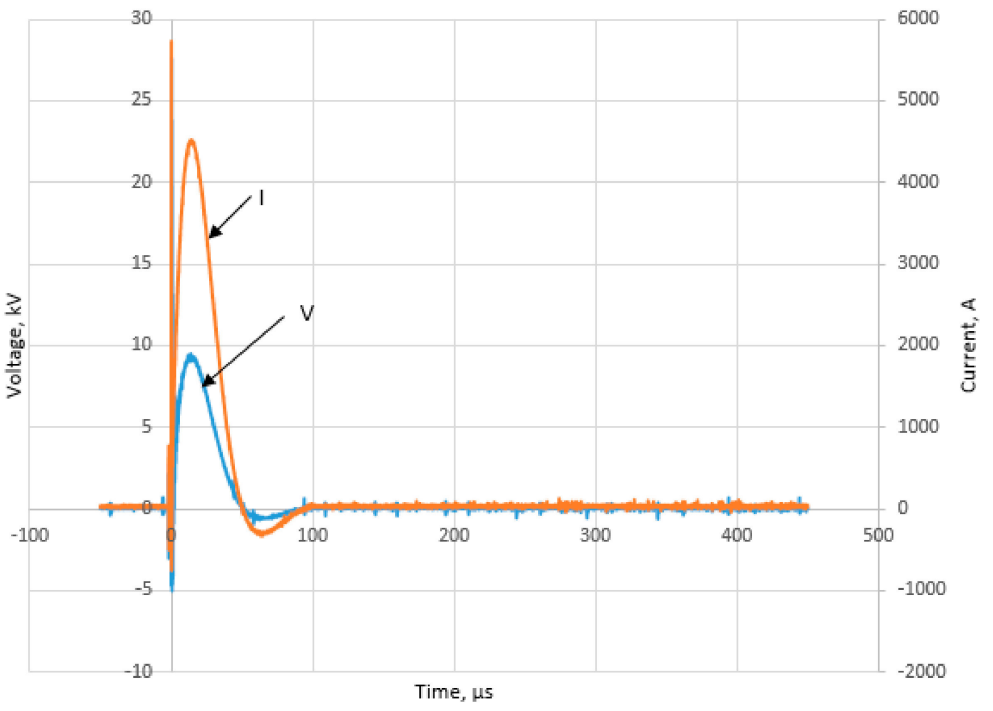

Figure 8. Voltage and current traces of positive polarity for electrodes installed at site 4 at a charging voltage of $30 \mathrm{kV}$. 


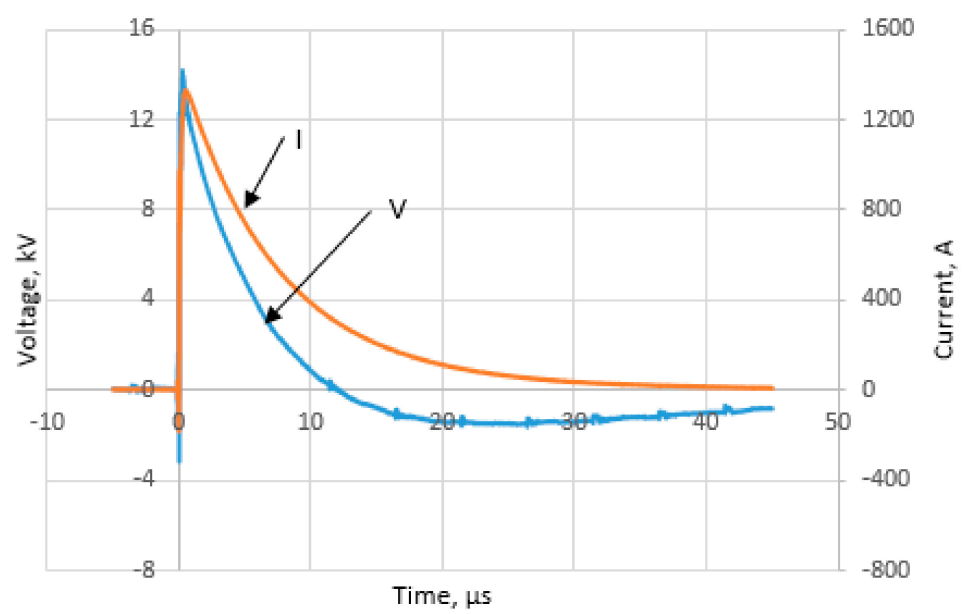

Figure 9. Voltage and current traces of positive polarity for sample A at a charging voltage of $120 \mathrm{kV}$.

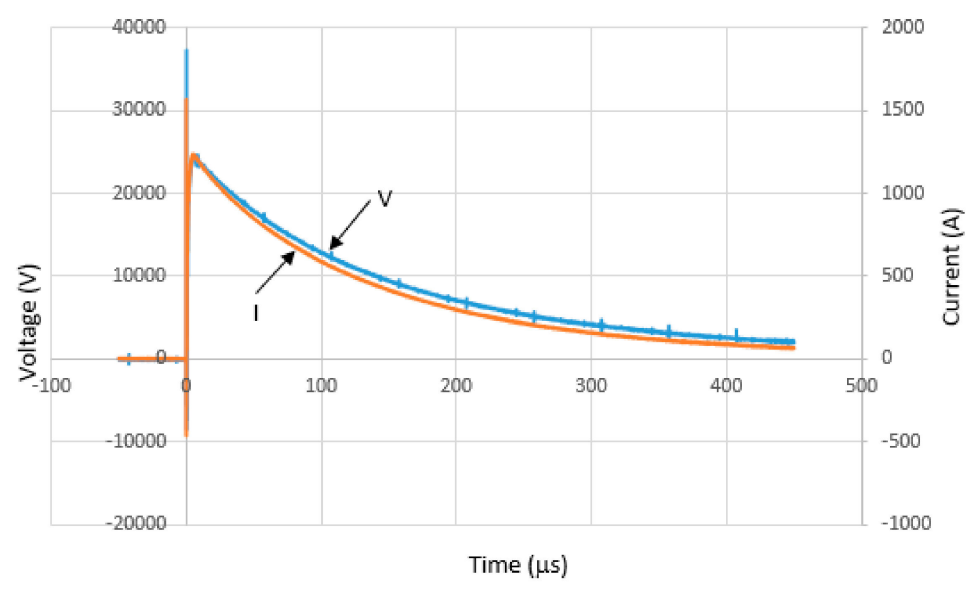

Figure 10. Improved voltage and current traces positive polarity for sample $C$, at a charging voltage of $50 \mathrm{kV}$.

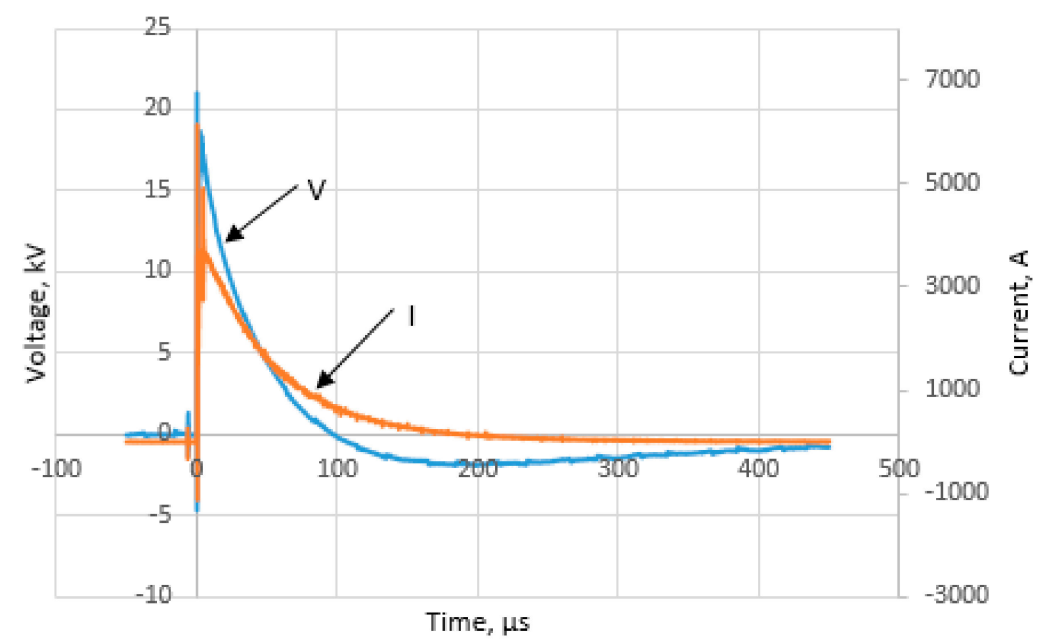

Figure 11. Voltage and current traces of positive polarity for sample A at a charging voltage of $180 \mathrm{kV}$. 


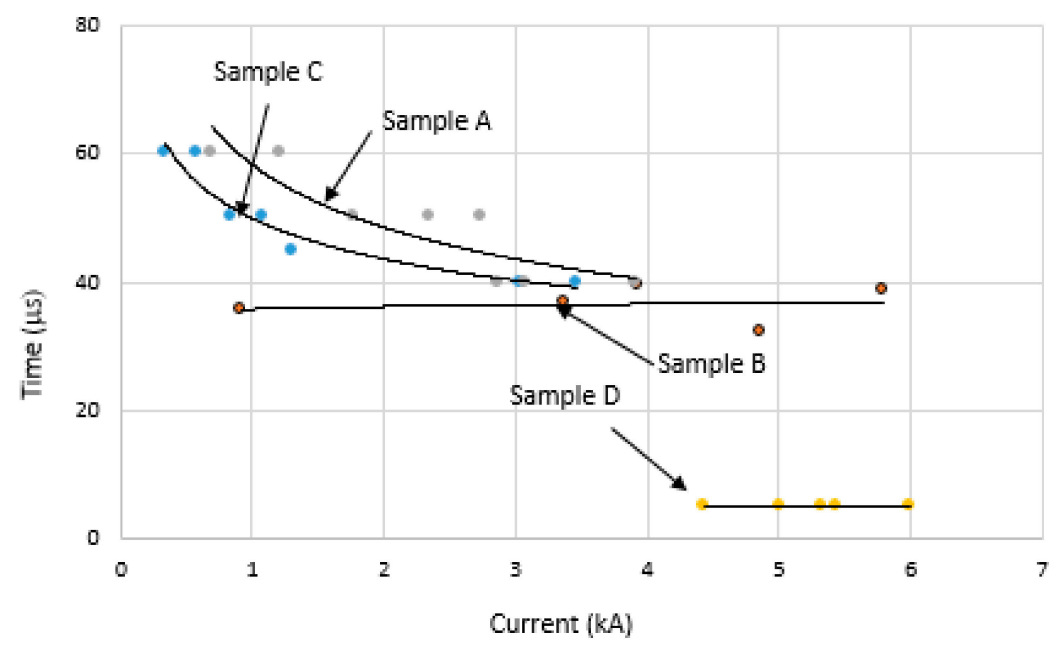

Figure 12. Time to discharge to zero for current against peak current for 4-rod electrodes installed at sites 1, 2, 3 and 4 under positive polarity.

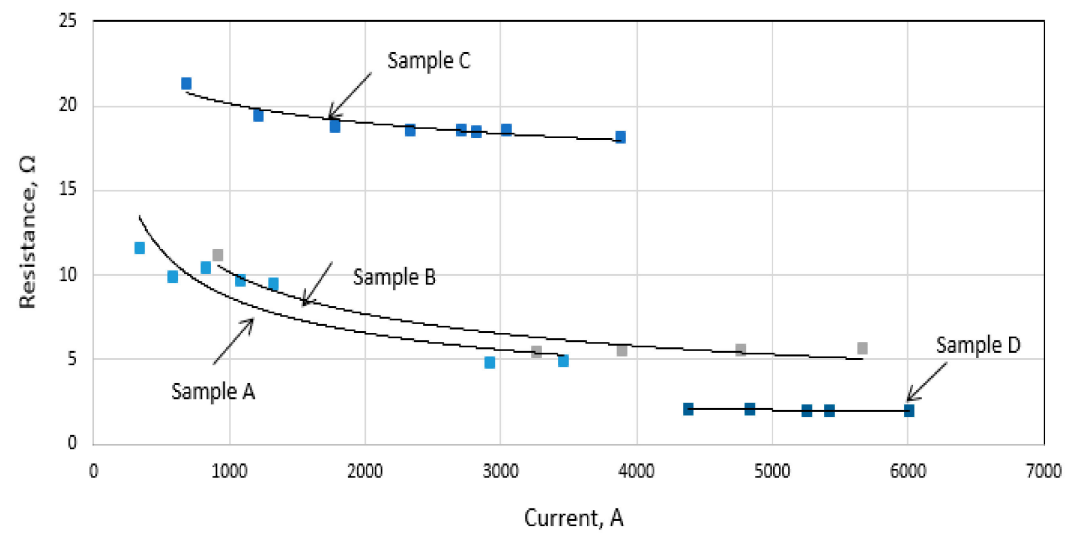

Figure 13. Impulse resistances for electrodes installed in different soil resistivity under positive impulse polarity.

\subsection{Effect of Impulse Polarity}

Experimental studies on the impulse characteristics of ground electrodes under both impulse polarities are usually based on laboratory experiments. Such studies are useful for understanding the soil characteristics under both impulse polarities in controlled conditions. In order to have a better understanding of the soil ionization phenomena in real-world conditions, it is important to carry out impulse tests on the practical sites under both impulse polarities.

4-rod ground electrodes that were installed at test sites, previously tested under positive polarity, presented in Section 3.2, were also tested under negative polarity on the same day. Both voltage and current impulse shapes for negative impulses were found to be similar to the positive polarity traces, shown in Figures 14-17 for samples A, B, C and D, respectively, at a charging voltage of $30 \mathrm{kV}$. Some oscillations on the voltage trace for Sample A, as noticed for positive polarity, was also noticed for negative polarity (see Figure 14).

Similar observations to those of positive polarity were seen for the current traces of negative polarity, where at certain voltage/current levels, initial oscillations were seen on the front current trace. The voltage at which these oscillations started to appear on the current trace were found to be different for each sample. Again, as can be found in positive polarity, there was no oscillation on the current trace, even at a charging voltage up to $180 \mathrm{kV}$, with the current reaching $4000 \mathrm{~A}$ for Sample C. Table 3 summarizes the charging and applied voltage, and the current trace at which the oscillations started to appear on the front current impulse for both impulse polarities. 
Table 3. Levels of Charging Voltage $\left(\mathrm{V}_{\mathrm{ch}}\right)$, Applied Voltage $\left(\mathrm{V}_{\mathrm{app}}\right)$ and Peak Current $\left(\mathrm{I}_{\mathrm{p}}\right)$ at which Oscillation Starts to Appear on the Current Trace.

\begin{tabular}{ccccccc}
\hline \multirow{2}{*}{ Sample } & \multicolumn{3}{c}{ Positive } & \multicolumn{3}{c}{ Negative } \\
\cline { 2 - 7 } & $\mathbf{V}_{\mathbf{c h}} \mathbf{( k V )}$ & $\mathbf{V}_{\mathbf{a p p}} \mathbf{( k V )}$ & $\mathbf{I}_{\mathbf{p}} \mathbf{( A )}$ & $\mathbf{V}_{\mathbf{c h}} \mathbf{( k V )}$ & $\mathbf{V}_{\mathbf{a p p}} \mathbf{( k V )}$ & $\mathbf{I}_{\mathbf{p}} \mathbf{( A )}$ \\
\hline $\mathrm{A}$ & 150 & 16 & 2934 & 100 & 12 & 2800 \\
$\mathrm{~B}$ & 50 & 12 & 3200 & 50 & 17 & 3200 \\
$\mathrm{C}$ & & No Oscillations & & & No Oscillations & \\
$\mathrm{D}$ & 40 & 12.5 & 6000 & 37 & 11 & 5852 \\
\hline
\end{tabular}

However, for each test sample, the times to discharge to zero were found to be higher under negative impulses compared with those under positive impulses. Figure 18 illustrates the differences between times to discharge to zero for samples A, B, C and D under both polarities. As can be seen from the figure, inconsistency in the results was noted where, sample $C$ had the higher time to discharge to zero of current impulse under negative polarity than positive polarity, which is similar to findings obtained from other literature $[10,11]$. On the other hand, the times to discharge to zero for samples A and B were higher in positive polarity than with a negative polarity impulse. Similar time to discharge to zero of the current trace was noted for Sample D.

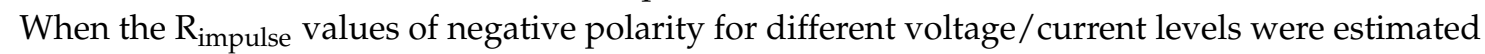
using the earlier formula presented in Section 3.1, as (1), the $R_{\text {impulse }}$ values of negative impulse were found to be higher for negative impulse polarity than for positive impulse polarity for Sample C,

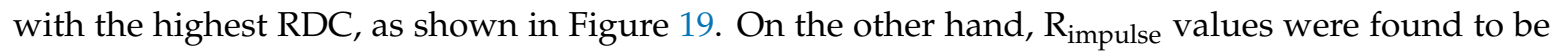
lower for positive polarity than for negative polarity for sample $A$, and $R_{\text {impulse }}$ values were found to be independent of impulse polarity with lower RDC (samples B and D). These results agree with those published by Cabrera et al. [11] in which the $R_{\text {impulse }}$ values of soil under negative impulse polarity was higher than that for positive impulse polarity for high resistivity soil, and impulse polarity became independent in low soil resistivity, hence lower RDC.

The difference in impulse polarity was possible since in high resistivity soil, larger air voids are expected than in low resistivity soil, which mostly filled up with water and the composition of the soil is more compact. As is generally known, air discharges/breakdown are affected by impulse polarity [16]. Thus, due to larger air voids in high resistivity soil, impulse polarity is likely to affect the discharges in the air in higher resistivity soil than in low resistivity soil, with smaller air voids. In this study, Site 3 had the highest soil resistivity, which expectedly had more air voids than the other three sites, which had some impulse polarity effect as compared to the other three sites/samples.

These results revealed that the design of grounding systems need to consider the ionization process under both impulse polarities, especially in high resistivity soil.

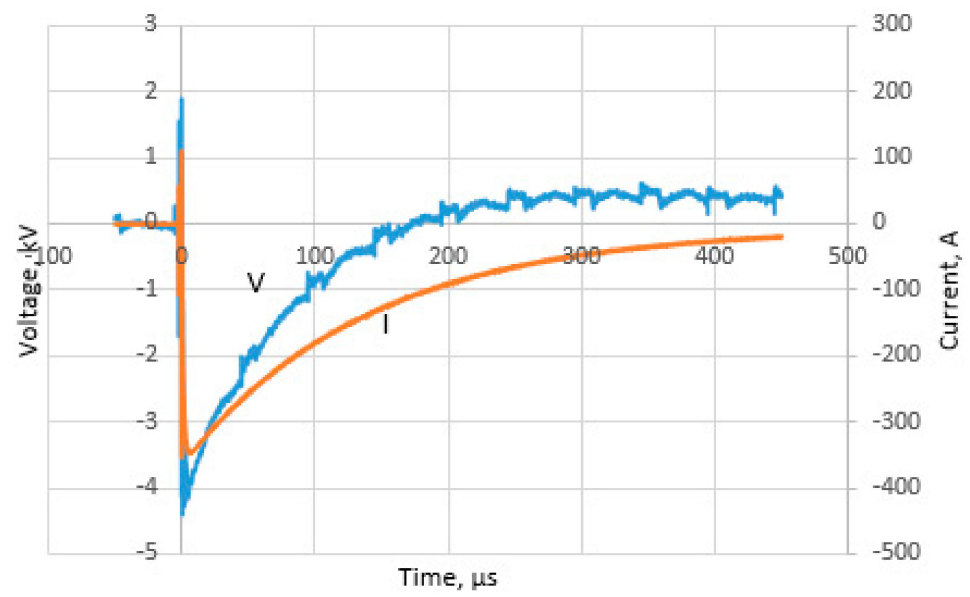

Figure 14. Voltage and current traces of negative polarity for electrodes installed at site 1, at a charging voltage of $30 \mathrm{kV}$. 


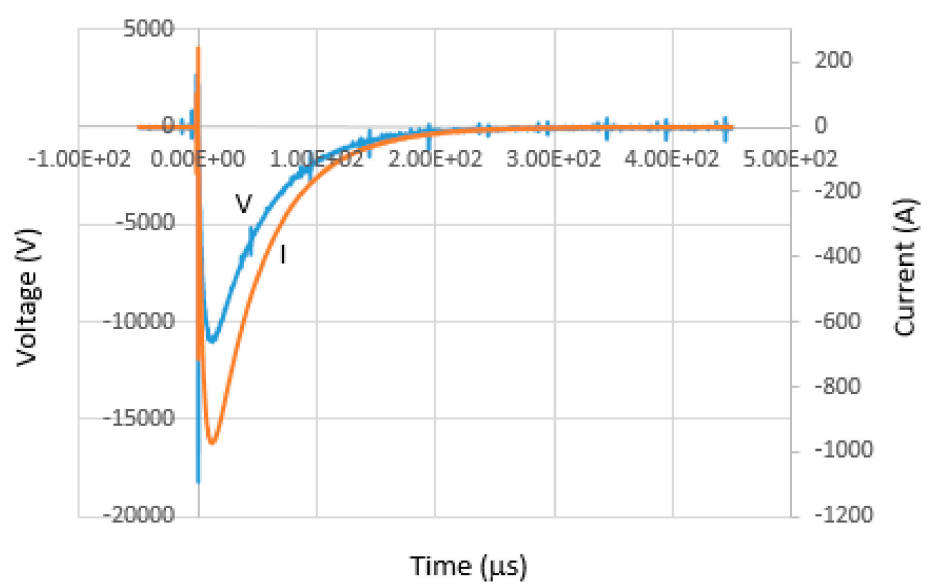

Figure 15. Voltage and current traces of negative polarity for electrodes installed at site 2 , at a charging voltage of $30 \mathrm{kV}$.

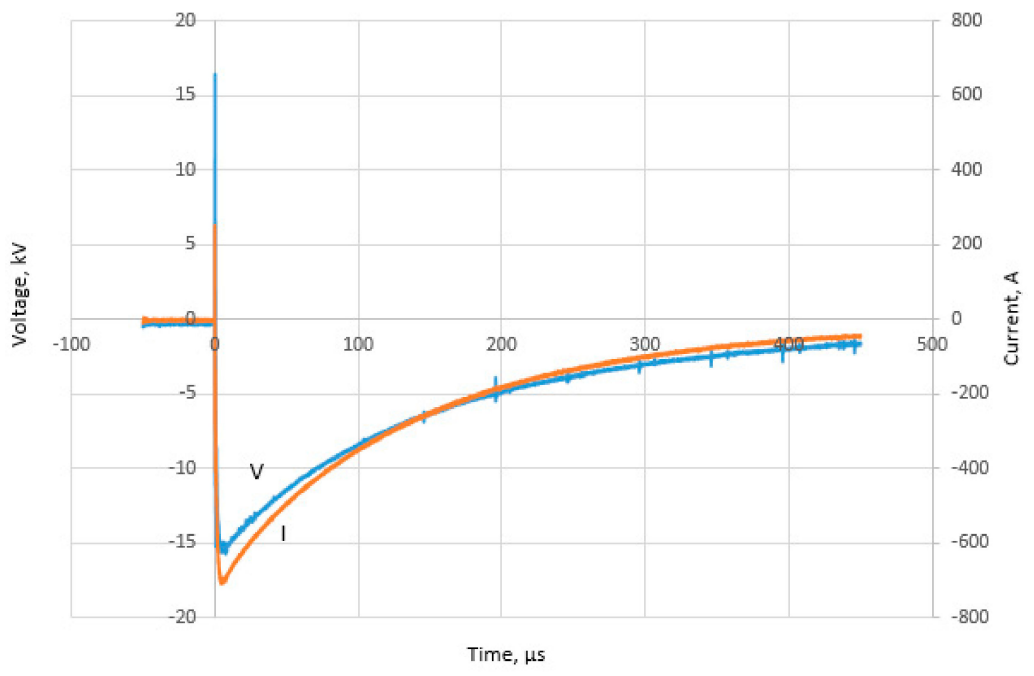

Figure 16. Voltage and current traces of negative polarity for electrodes installed at site 3 , at a charging voltage of $30 \mathrm{kV}$.

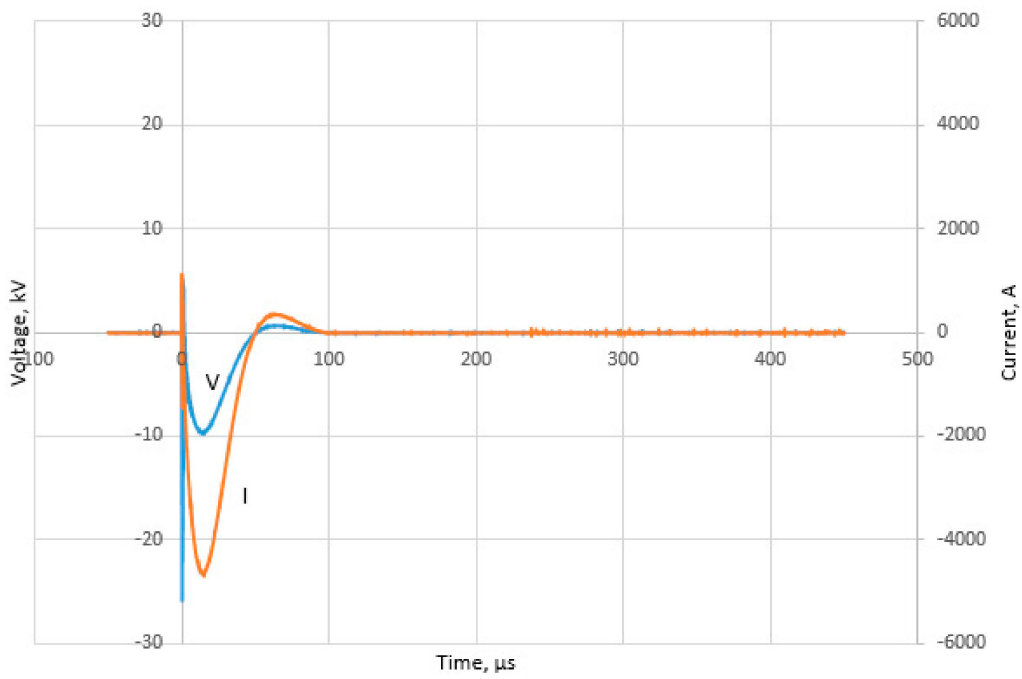

Figure 17. Voltage and current traces of negative polarity for electrodes installed at site 4 , at a charging voltage of $30 \mathrm{kV}$. 


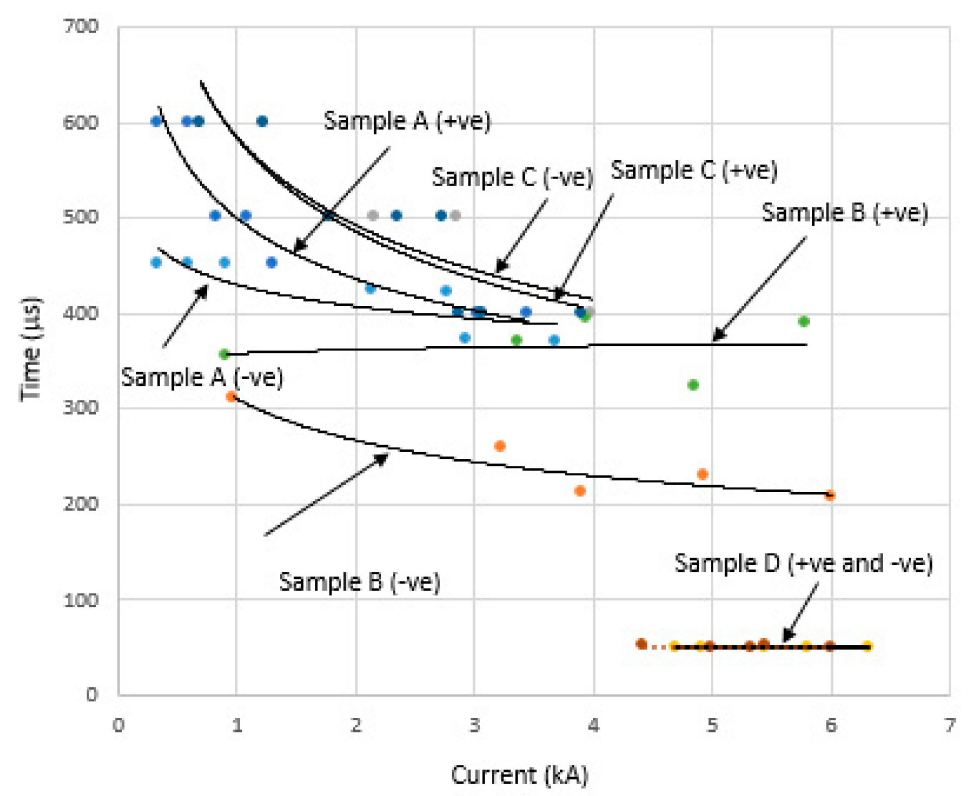

Figure 18. Time to discharge to zero of current trace against peak current for 4-rod electrodes installed at sites 1, 2, 3 and 4, under both impulse polarities.

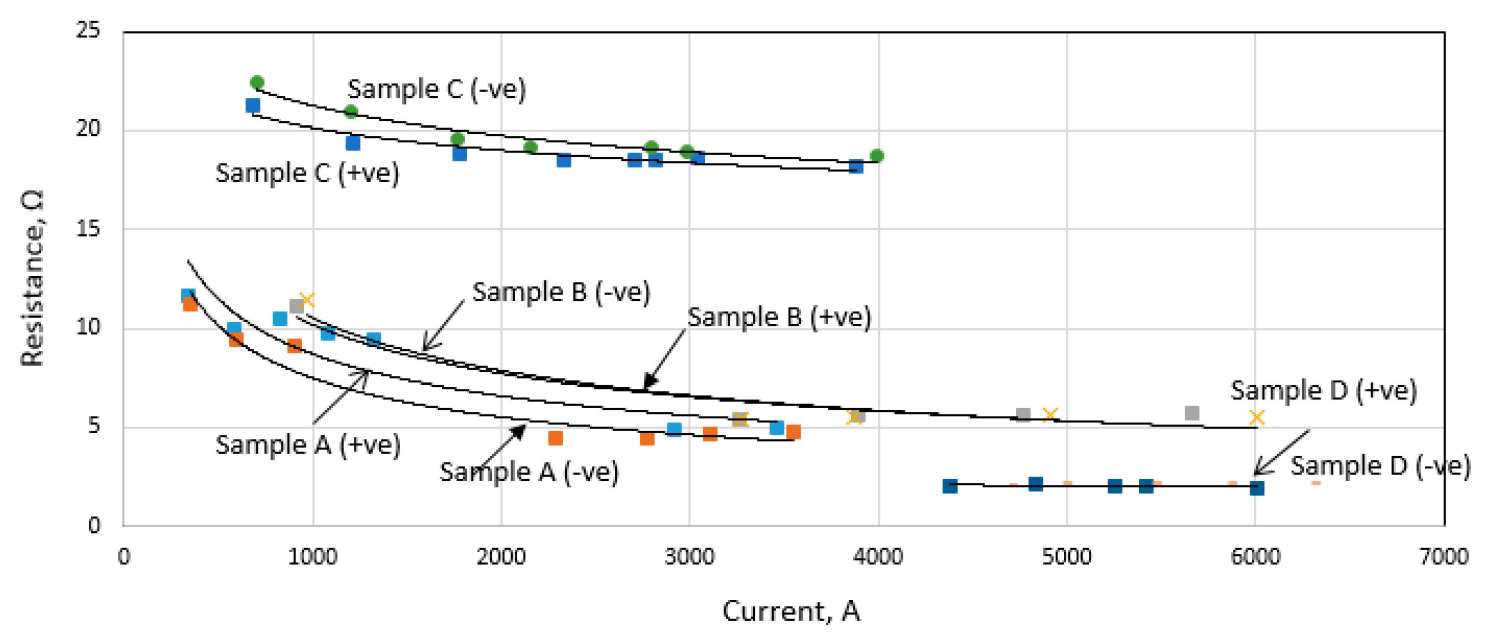

Figure 19. Impulse resistances for electrodes installed in different soil resistivities.

\subsection{Effect of Electrode's Configurations}

There are two parameters that should be considered in designing an earthing system; electrode geometry and soil properties. In earlier sections (Sections 3.1 and 3.2), the effects of impulse current on soil resistivity and impulse polarity on values were investigated using a typical $2 \mathrm{~m} \times 2 \mathrm{~m}$ earthing grid (shown in Figure 1), installed at four different sites, with different soil resistivities. That way, with the same earth electrode's configuration, the effect of high impulse current on soil resistivity and impulse polarity could be investigated more closely.

In order to determine the effect of earth electrode configuration, a few earthing systems were installed at site 1, consisting of a single-rod, 2-rod and 3-rod electrodes. The detail of size/configurations were presented in Section 2.1 of this paper. Impulse tests were first started with 1-rod electrode. As for the 2-rod electrodes, another rod electrode was installed $3 \mathrm{~m}$ away from the 1-rod and connected by a copper mesh, and arranged in one alignment. Similarly, for 3-rod electrodes, another rod electrode was installed $3 \mathrm{~m}$ away from the 2-rod electrode, and connected by copper mesh, arranged in one alignment.

Figures 20-22 show the voltage and current records for 1-rod, 2-rod and 3-rod electrodes, respectively, all at a charging voltage of $30 \mathrm{kV}$. Similar voltage and current traces were noted at higher voltage/current levels. As can be seen in the figures, the current trace shape appears to coincide with that of voltage, 
indicating a linear resistive behaviour. It was also noted that the time to discharge to zero of the current trace was shorter in 3-rod electrodes, and at higher current levels, due to better conduction in larger size of grounding systems and at higher voltage/current levels. Figure 23 illustrates the differences in time to discharge to zero of current trace for 1-rod, 2-rod and 3-rod electrodes, and as can be seen, up to a 50\% difference can occur between 1-rod, and 3-rod electrodes. No sign of an inductive effect was seen in this study, despite the 3-rod electrode having bigger dimensions than 1 and 2-rod electrodes.

The impulse resistance, $R_{\text {impulse }}$ was also measured as a ratio of peak voltage, $V_{p}$ to the peak current, $I_{p}$, as used in Section 3.1 and 3.2. Figure 24 shows the $R_{\text {Impulse }}$ for 1-rod, 2-rod and 3-rod electrodes at the same site 1 . As can be seen, the $\mathrm{R}_{\text {Impulse }}$ curve had a similar trend to those obtained earlier, Sections 3.1 and 3.2, and similar to that found in previously published work [1-10], in which the $\mathrm{R}_{\text {Impulse }}$ values were found to be decreasing with increasing current magnitudes. Moreover, all of the $R_{\text {impulse values were }}$ also found to be lower than that of their corresponding RDC, presented in Table 1. This was explained by ionisation in the soil, which relatively reduces $R_{\text {Impulse. }}$. The highest reduction of $R_{\text {impulse }}$ resistance from its RDC was found to be in a 1-rod electrode, which was around $70 \%$, and around $50 \%$ for 2-rod and 3-rod electrodes.

At higher current magnitudes, above $2 \mathrm{kA}, \mathrm{R}_{\text {Impulse }}$ values were found to be close and almost constant, independent of the earth electrode configurations. The results were similar to the results found in the literature $[1-3,7,8]$ where the reduction is the highest in high RDC, and at lower current magnitudes. However, in those studies [1-3], various configurations grounding systems were installed at different sites, with different soil resistivities. In this paper, similar soil resistivities were used, and only electrode configurations were changed. The results also revealed that it is possible to consider reducing the size of the earth electrode in the design of grounding systems, in order to achieve the highest ionisation effect.

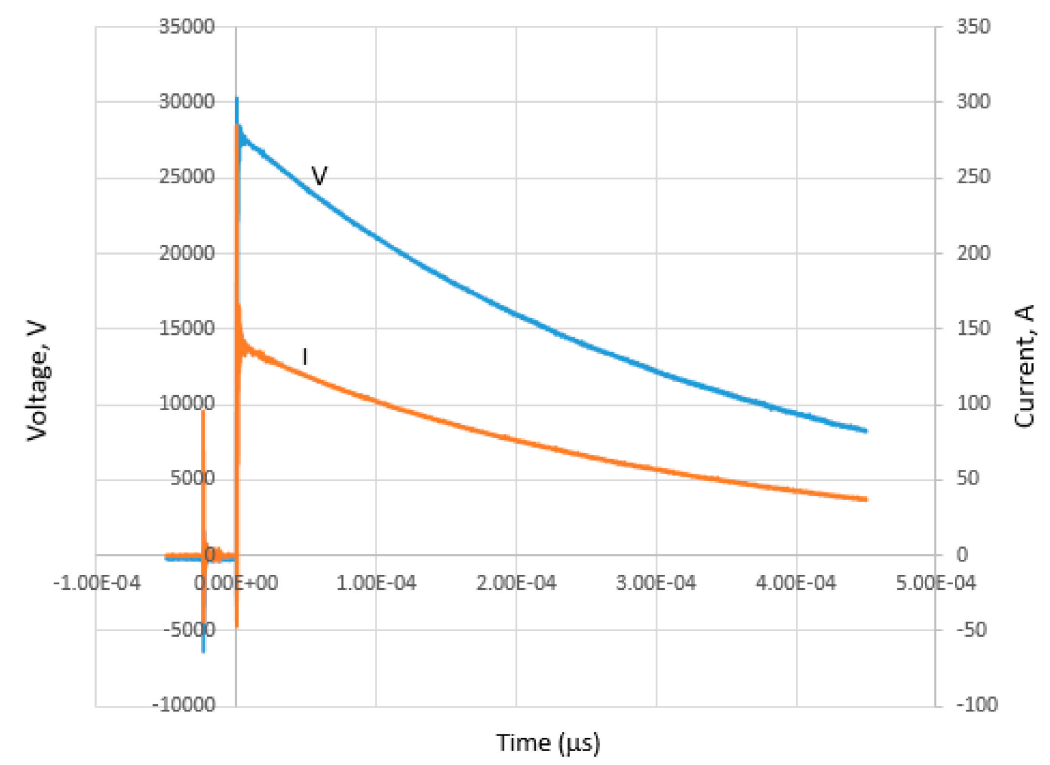

Figure 20. Voltage and current traces of 1-rod, at a charging voltage of $30 \mathrm{kV}$. 


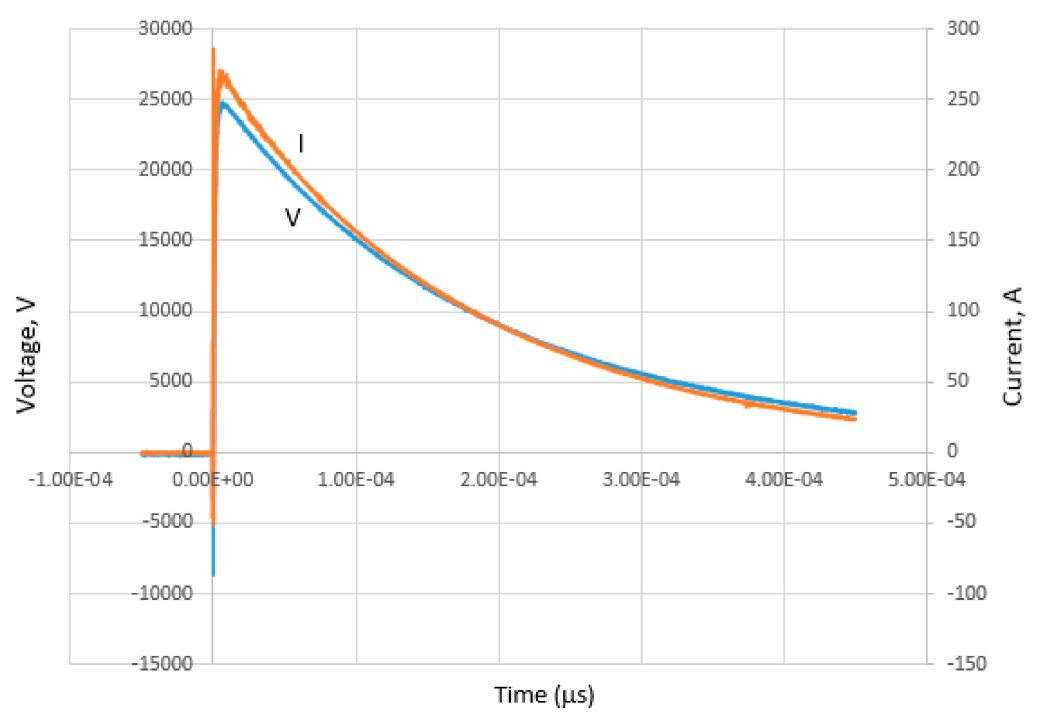

Figure 21. Voltage and current traces of 2-rod, at a charging voltage of $30 \mathrm{kV}$.

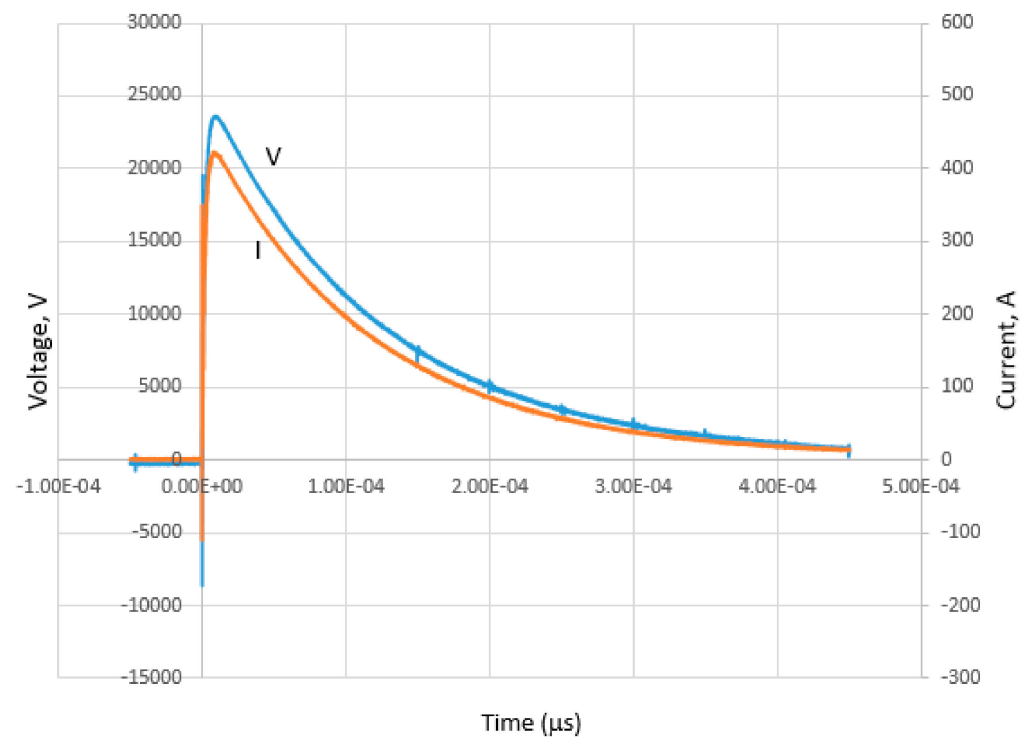

Figure 22. Voltage and current traces of 3-rod electrodes, at a charging voltage of $30 \mathrm{kV}$.

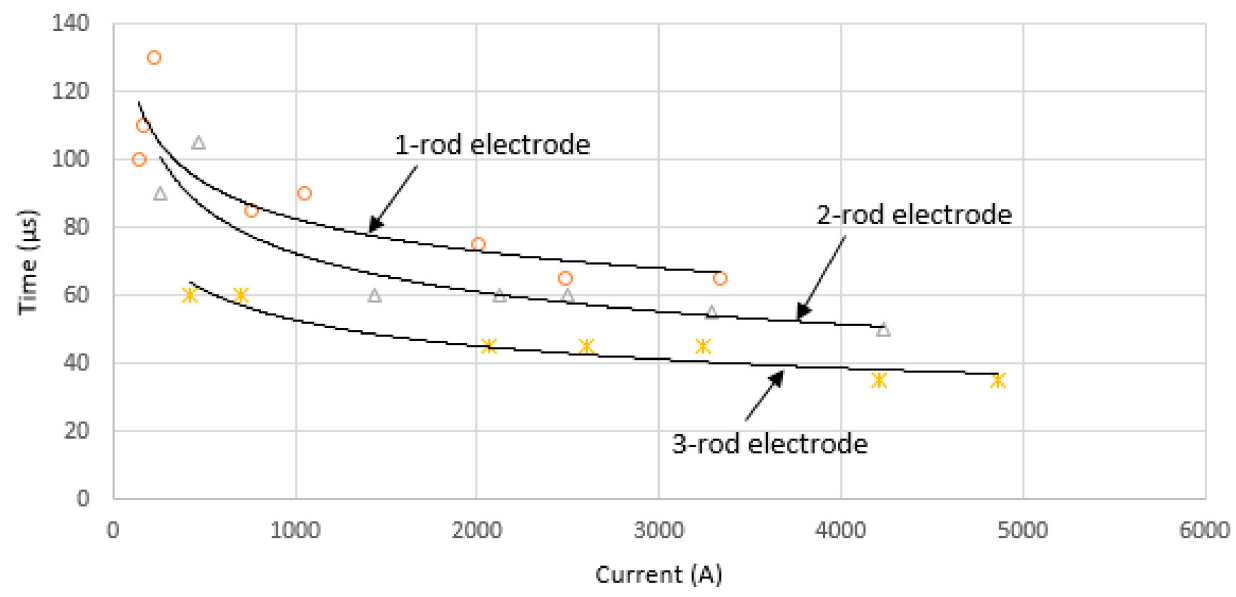

Figure 23. Time to discharge to zero for current against peak current for 1-rod, 2-rod and 3-rod electrodes installed at sites 1, 2,3 and 4 . 


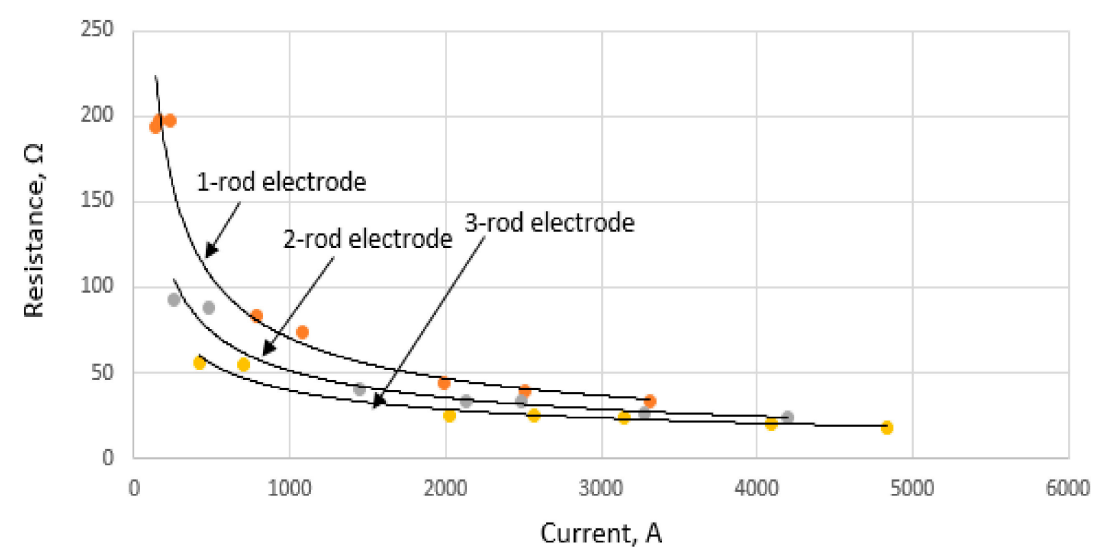

Figure 24. Impulse resistances for 1-rod, 2-rod and 3-rod electrodes.

\section{Conclusions}

A field test set-up was used to investigate the performance of grounding systems under various factors, namely; soil resistivity, impulse polarity and earth electrode conditions. It was found that $R_{\text {impulse }}$ of high soil resistivity decreases with increasing currents, and $R_{\text {impulse }}$ was found constant in low soil resistivity. The decrease of earth resistance values in high resistivity soil was due to the ionisation process in soil. In addition, it was found that the time to discharge to zero for the current traces was the slowest in high resistivity soil, due to high resistance in high resistivity soil. Moreover, the slower discharging time of the current traces at low charging voltage could be associated with a low ionisation/conduction process at low voltage/current levels.

Difference in $R_{\text {impulse }}$ for different impulse polarity was only observed in high resistivity soil, where $R_{\text {impulse }}$ was higher under negative impulse conditions. This observation was explained by the ionisation process that occurred more in high resistivity soil which has more air voids trapped within the soil than in low resistivity soil. It was also observed that under a negative impulse, the current trace had longer times-to-discharge to zero. When the effect of the earth electrode configuration was investigated, it was observed that 3-rod electrodes had lower reductions of $R_{\text {impulse }}$ for a given applied voltage.

Analysis of test data revealed that it is considerably acceptable to have the grounding installation in high resistivity soil, and it is not necessarily needed to enlarge the dimension of earthing systems, since the earth resistance will reduce with currents for grounding systems in high resistivity soil, due to the ionization process in soil. This paper suggests that since it is difficult in some grounding to have low RDC in high resistivity soil, the engineers can consider the ionization process in earthing system design, where ionization is more likely to take place and can reduce the impulse earth resistance for earth electrodes in high soil resistivity. However, undoubtedly, this is an initial stage of study. Despite the advantage of ionization for grounding systems in high resistivity soil, it was noted that time to discharge to zero for grounding systems installed in high resistivity soil was higher than that for earth electrodes in low resistivity soil. Some improvements can be made in terms of time to discharge to ground for earthing systems in high soil resistivity, which is higher than that of low soil resistivity, in relation to the design of grounding systems. With this testing and analysis on practical grounding systems under various effects, the authors hope the design of grounding systems can be developed and proof tested in future, considering and ensuring soil ionization process would occur. It is hoped this research can reduce the lightning back-flashover due to inadequate design of grounding systems in the near future.

Author Contributions: M.S.R., N.M.N., N.N.A. and S.A. were involved in setting up the experiment; M.S.R. analyzed the data; N.M.N. helped with validation of analysis.

Funding: This research was funded by TELEKOM MALAYSIA RESEARCH AND DEVELOPMENT (TMR\&D), grant number MMUE170005 and MMUE180008.

Conflicts of Interest: The authors declare no conflict of interest. 


\section{References}

1. Sekioka, S.; Sonoda, T.; Ametani, A. Experimental study of current dependent grounding resistance of rod electrode. IEEE Trans. Power Deliv. 2005, 20, 1569-1576. [CrossRef]

2. Sekioka, S.; Hayashida, H.; Hara, T.; Ametani, A. Measurement of grounding resistance for high impulse currents. IEE Proc. Gener. Transm. Distrib. 1998, 145, 693-699. [CrossRef]

3. Yunus, S.; Mohamad Nor, N.; Agbor, N.; Abdullah, S.; Ramar, K. Performance of earthing systems for different earth electrode configurations. IEEE Trans. Ind. Appl. 2015, 51, 5335-5342. [CrossRef]

4. Yang, S.; Zhou, W.; Huang, J.; Yu, J. Investigation on impulse characteristic of full-scale grounding grid in substation. IEEE Trans. Electromagn. Compat. 2017, 60, 1993-2001. [CrossRef]

5. Haddad, A.; Griffiths, H.; Ahmeda, M.; Harid, N. Experimental Investigation of the Impulse Characteristics of Practical Ground Electrode Systems. In Proceedings of the International Conference on High Voltage Engineering and Application, New Orleans, MS, USA, 11-14 October 2010.

6. Duan, L.; Zhang, B.; He, J.; Xiao, L.; Qian, L. Experimental Study on Transient Characteristics of Grounding Grid for Substation. In Proceedings of the 33rd International Conference of Lightning Protection (ICLP), Estoril, Portugal, 25-30 September 2016.

7. Etobi, A.; Mohamad Nor, N.; Abdullah, S.; Othman, M. Characterizations of a Single Rod Electrode under High Impulse Currents with Different Polarities. In Proceedings of the 1st IEEE International Conference on Electrical Materials and Power Equipment (ICEMPE), Xi'an, China, 14-17 May 2017.

8. Abdullah, S.; Mohamad Nor, N.; Ramar, K. Field measurements on earthing systems of different soil resistivity values under high impulse conditions. Electr. Eng. 2017, 99, 1005-1011. [CrossRef]

9. Nor, N.M.; Haddad, A.; Griffiths, H. Characterization of ionization phenomena in soils under fast impulses. IEEE Trans. Power Deliv. 2006, 21, 353-361. [CrossRef]

10. Mohamad Nor, N.; Haddad, A.; Griffiths, H. Factors Affecting Soil Characteristics under Fast Transients. In Proceedings of the International Conference of Power Systems Transients (IPST), New Orleans, MS, USA, 2003; Available online: http:/ / www.ipstconf.org/papers /Proc_IPST2003/03IPST07-05.pdf (accessed on 11 July 2018).

11. Cabrera, M.; Lundquist, S.; Cooray, V. On the physical properties of discharges in sand under lightning impulses. J. Electrost. 1993, 30, 17-28.

12. ANSI/IEEE Std 81-2012. IEEE Guide for Measuring Earth Resistivity, Ground Impedance, and Earth Surface Potentials of a Ground System. Available online: https:/ / ieeexplore.ieee.org/document/6392181 (accessed on 31 July 2018).

13. ANSI/IEEE Std 80-2000. IEEE Guide for Safety in AC Substation Grounding. Available online: http: / / www.dee.ufrj.br/ acsl/grad/equipamentos/IEEE-std80.pdf (accessed on 30 July 2018).

14. Heimbach, M.; Grcev, L.D. Grounding systems analysis in transient programs applying electromagnetic field approach. IEEE Trans. Power Deliv. 1997, 12, 186-193. [CrossRef]

15. Grcev, L. Lightning surge efficiency of grounding grid. IEEE Trans. Power Deliv. 2011, 26, 1692-1699. [CrossRef]

16. Kuffel, E.; Zaengl, W.S.; Kuffel, J. HV Engineering Book; Elsevier: Amsterdam, The Netherlands, 2000.

(C) 2018 by the authors. Licensee MDPI, Basel, Switzerland. This article is an open access article distributed under the terms and conditions of the Creative Commons Attribution (CC BY) license (http:// creativecommons.org/licenses/by/4.0/). 